\title{
Effects of calcination temperatures on the morphology, architecture and dielectric properties of BCZT ceramics
}

\author{
RUI LIU ${ }^{1,2, *} \mathbb{D}$, YINGJIE QIAO ${ }^{2}$, XIAOHONG ZHANG ${ }^{2}$ and CHEN-XI LU ${ }^{2}$ \\ ${ }^{1}$ China School of Science, Harbin University of Commerce, Harbin 150076, People's Republic of China \\ ${ }^{2}$ College of Materials Science and Chemical Engineering, Harbin Engineering University, Harbin 150001, \\ People's Republic of China \\ *Author for correspondence (57776806@qq.com)
}

MS received 20 August 2018; accepted 11 December 2018; published online 4 May 2019

\begin{abstract}
Ba}_{0.85} \mathrm{Ca}_{0.15}\right)\left(\mathrm{Zr}_{0.1} \mathrm{Ti}_{0.9}\right) \mathrm{O}_{3}(\mathrm{BCZT})$ ceramics were prepared by a simple sol-gel method. The effects of calcining temperature on the formation of BCZT ceramics were investigated in detail. The morphological changes and phase transformation of BCZT ceramics were analysed by X-ray diffraction and scanning electron microscopy. It is found that the calcined temperature determines the formation of a crystal phase, crystallinity and grain size. For dielectric properties, dielectric constant was increased first, and then decreased with increasing calcination temperature, in which the maximum dielectric constant of 2732 was achieved at $650^{\circ} \mathrm{C}$ under a low-frequency alternating electric field. This may be attributed to the high crystallinity, density and fewer surface defects of BCZT ceramics. The optimum calcination temperature helps to understand the dielectric properties, which indicates that BCZT ceramics are promising lead-free candidates for widely used lead-based piezoelectric materials.
\end{abstract}

Keywords. BCZT ceramics; calcination temperatures; sol-gel method; dielectric properties.

\section{Introduction}

Since $\left(\mathrm{Ba}_{0.85} \mathrm{Ca}_{0.15}\right)\left(\mathrm{Zr}_{0.1} \mathrm{Ti}_{0.9}\right) \mathrm{O}_{3} \quad(\mathrm{BCZT})$ piezoelectric ceramics were reported, they have been commonly used in applications of sensors, ultrasonic motors, buzzers and so on [1-4]. BCZT piezoelectric ceramics have attracted extensive attention due to their unique structure [5,6]. Many attempts have been made to treat BCZT in these aspects, including changing methods of synthesis [7,8], modifying BCZT piezoelectric ceramics $[9,10]$ and treating temperatures [11,12]. Yap et al [7] reported that BCZT ceramics were fabricated using the sacrificial fugitive technique, where increasing porosity led to decreasing ferroelectric and piezoelectric properties due to a reduction of polarizable BCZT ceramic. Liu et al [9] showed that $1 \mathrm{~mol} \% \mathrm{Sr}$ and $1 \mathrm{~mol} \%$ Sn co-doped $\left(\mathrm{Ba}_{0.84} \mathrm{Ca}_{0.15} \mathrm{Sr}_{0.01}\right)\left(\mathrm{Ti}_{0.90} \mathrm{Zr}_{0.09} \mathrm{Sn}_{0.01}\right) \mathrm{O}_{3}$ ceramics were prepared by the conventional solid-state reaction method, in which it exhibited excellent electrical properties. This can be attributed to the morphotropic phase boundary effect and the dense microstructure induced by $\mathrm{Sr}$ and Sn co-doping. Kantha et al [11] fabricated BCZT ceramics by the solid reaction method. The effect of the sintering method on the microstructure and dielectric properties of lead-free BCZT ceramics were investigated systematically. However, some mechanical defects still make them susceptible to dielectric breakdown and mechanical failure $[13,14]$. The sol-gel method is an environmentally friendly method to prepare materials in different areas. Moreover, we set to seek more effective dielectric constant and dielectric loss. Both dielectric constant and dielectric loss of BCZT ceramics are two crucial factors $[13,14]$.

However, heat treatment is also very important for applications, which can promote crystallinity and convert it to a more active crystal phase [15]. Calcination of BCZT leads to a change of the grain size, morphology, crystal structure, phase compositions and dielectric properties. Yu and Wang [16] examined the influence of calcination temperature on the morphology, crystal phase, crystalline process and photo-electrochemistry properties in detail. Liao et al [17] found different post-heating treatment schemes which greatly affected photo-catalytic activity by changing the phase structure and morphological properties.

In this work, BCZT ceramics were synthesized by a simple sol-gel method. Effects of calcination temperatures on the crystal phase, grain size, architecture, morphology and dielectric properties of BCZT ceramics were investigated systematically. The purpose of this work is to better understand the effects of calcination conditions on the formation mechanism of BCZT ceramics.

\section{Experimental}

BCZT ceramics were prepared by the sol-gel method, in which stoichiometric ratios of $\mathrm{ZrOCl}_{2} \cdot 8 \mathrm{H}_{2} \mathrm{O}, \mathrm{Ca}\left(\mathrm{NO}_{3}\right)_{2} \cdot 4 \mathrm{H}_{2} \mathrm{O}$, 
$\mathrm{Ba}\left(\mathrm{CH}_{3} \mathrm{OO}\right)_{2}$ and $\mathrm{C}_{12} \mathrm{H}_{28} \mathrm{O}_{4} \mathrm{Ti}$ were mixed in anhydrous ethanol and acetic acid to obtain the gel of the BZTBCT $\left[\mathrm{Ba}\left(\mathrm{Zr}_{0.2} \mathrm{Ti}_{0.8}\right) \mathrm{O}_{3}\right]\left[\left(\mathrm{Ba}_{0.7} \mathrm{Ca}_{0.3}\right) \mathrm{TiO}_{3}\right]$ system (molar ratio of BCT-BZT is 50:50). Precursors were mixed intensively. With thermal insulation over a period of time, the sol becomes milky white. Calcination temperatures were ranged from 550 to $750^{\circ} \mathrm{C}$ for $4 \mathrm{~h}$. Then the calcined powders were pressed into pellets (using polyvinyl butyral as a binder) and sintered at $1400^{\circ} \mathrm{C}$ for $2 \mathrm{~h}$ in air.

\section{Results and discussion}

The crystal structures of BCZT ceramics with different calcination temperatures were analysed by X-ray diffraction (XRD). Figure 1 shows the XRD patterns of BCZT ceramics calcined at various temperatures for $4 \mathrm{~h}$, with a heating rate of $10^{\circ} \mathrm{C} \mathrm{min}^{-1}$. It can be seen that the degree of crystallization of the BCZT ceramic powder gradually increases as the calcining temperature increases. There are some uncrystallized impurity peaks at $550^{\circ} \mathrm{C}$, indicating that some oxides in the system have not participated in the reaction. When the BCZT ceramics were annealed at $600^{\circ} \mathrm{C}$, a typical perovskite structure began to appear in the XRD patterns. Most of the powders have been reacted and started to form the main crystal phase of BCZT at this temperature. The main crystal phase of BCZT ceramics is completely formed when the temperature was increased to $650^{\circ} \mathrm{C}$, indicating that the perovskite structure dominates the crystal phase. Upon increasing calcination temperatures, the peak tends to narrow, while the grain size will increase. The choice of calcination temperature should not only ensure that powder can be completely crystallized, but also ensure the excellent sintering performance. Therefore, it is reasonable to choose the above calcination temperature of $650^{\circ} \mathrm{C}$.

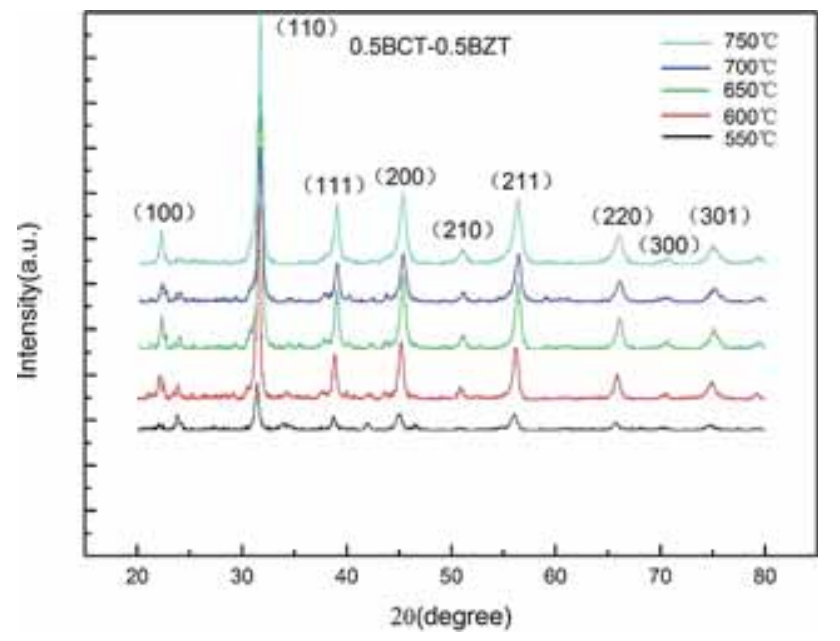

Figure 1. XRD patterns of BCZT ceramics at different calcination temperatures.

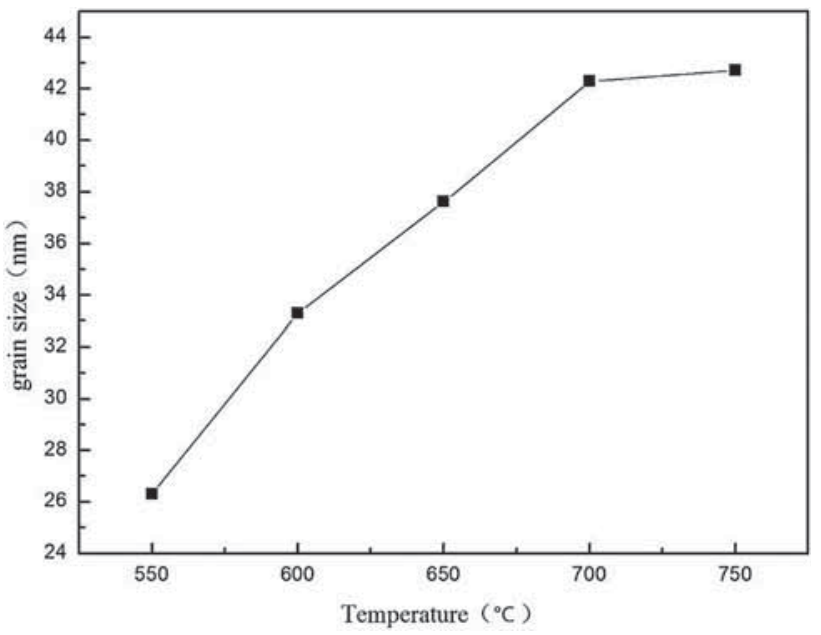

Figure 2. Grain size of BCZT ceramics at different calcination temperatures.

To further understand the mechanism of phase formation and the changes of dielectric properties, the grain size of BCZT ceramics was determined at different calcination temperatures as shown in figure 2 . The average crystalline sizes of BCZT ceramics were estimated using the XRD data and the equation (1):

$t=0.9 \lambda / B \cos \theta_{\mathrm{B}}$

where $t$ is the grain size, $B$ is a constant, $\lambda$ is the wavelength, $\theta_{\mathrm{B}}$ is the Bragg angle. The average grain size is only $26 \mathrm{~nm}$ at $550^{\circ} \mathrm{C}$. As the calcination temperature increases, the grain size rises rapidly between 550 and $700^{\circ} \mathrm{C}$, indicating that the formation nucleation process for rapid growth of the grain size has been completed entirely. When the temperature exceeds $700^{\circ} \mathrm{C}$, the rate of crystal nucleation begins to decrease. The grain size of the powder reached a maximum of $43 \mathrm{~nm}$. In fact, the experimental value of the grain size does not exceed $50 \mathrm{~nm}$, so this obtained value should be similar to the actual values.

Figure 3 shows SEM of BCZT ceramics annealed at different temperatures for $4 \mathrm{~h}$. As seen in figure $3 \mathrm{a}$, there is only a little agglomeration (most particles of the powder are uniform). The diameter of the agglomerates is in the range of $2 \sim 3 \mu \mathrm{m}$ annealed at $550^{\circ} \mathrm{C}$. It can be seen that the amount of powder agglomeration increases obviously with an increase in calcination temperature. Figure $3 b$ shows that most of the agglomerates consist of many small particles, which can be dispersed by the ultrasonic method. As seen in figure $3 \mathrm{~d}$, we can see that the growth of powder is obvious, due to the high activity of the powder prepared by the sol-gel method. Due to the increase of agglomeration, the uniformity of the powder is greatly reduced at an annealing temperature of $750^{\circ} \mathrm{C}$. Therefore, it is necessary for the 


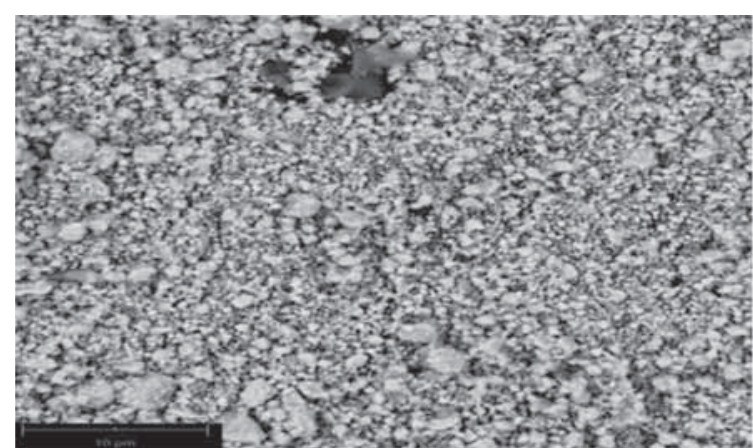

(a) $550^{\circ} \mathrm{C}$

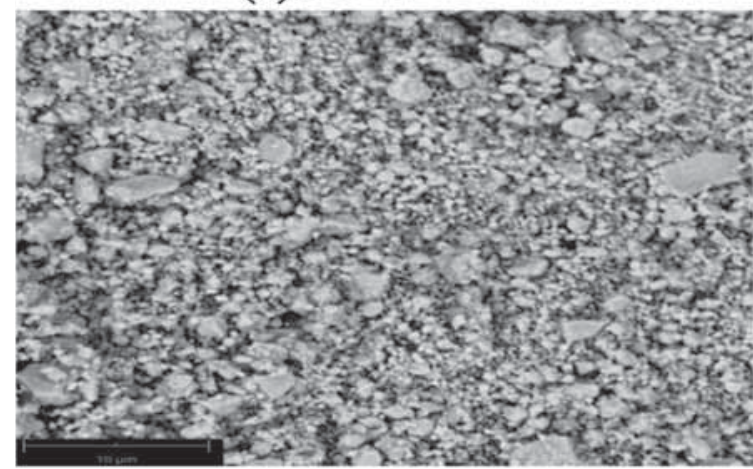

(c) $650^{\circ} \mathrm{C}$

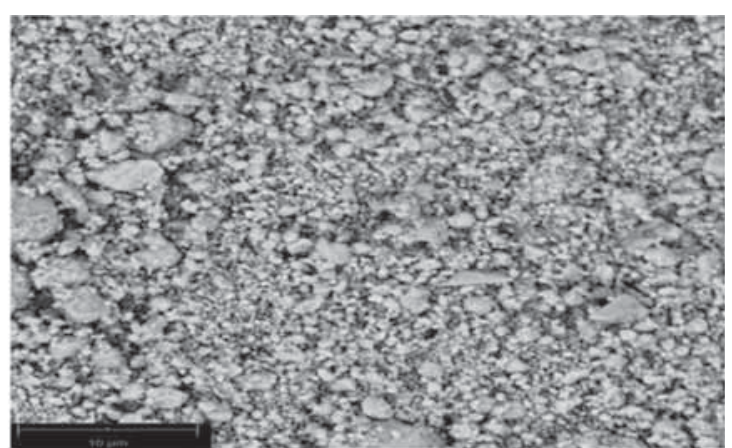

(b) $600^{\circ} \mathrm{C}$

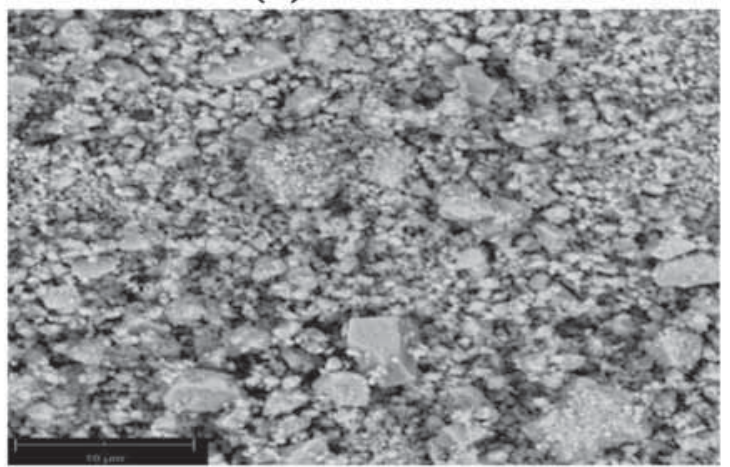

(d) $700^{\circ} \mathrm{C}$

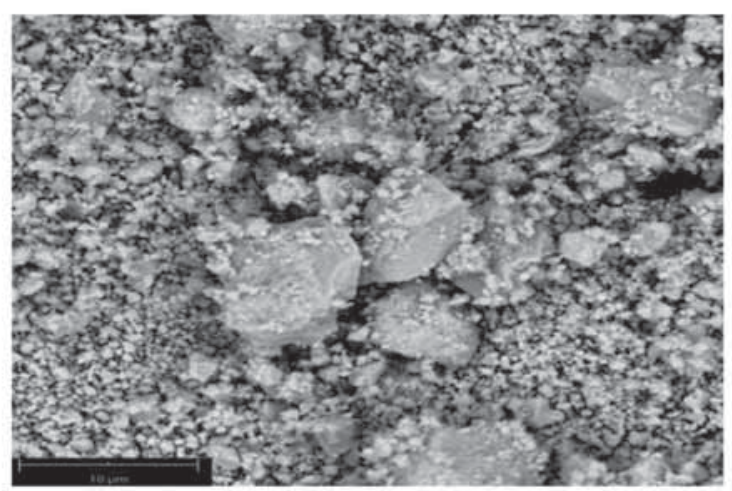

(e) $750^{\circ} \mathrm{C}$

Figure 3. The SEM images of BCZT ceramics calcinated at different calcination temperatures.

powder prepared by the sol-gel method to be dispersed after calcination.

Figure 4 shows the density of BCZT ceramics at different sintering temperatures. The density of BCZT ceramics measured by the Archimedes drainage method is shown in figure 4. The powders calcined at 650 and $750^{\circ} \mathrm{C}$ reached the maximum density at a sintering temperature of $1400^{\circ} \mathrm{C}$. When the calcination temperature was $650^{\circ} \mathrm{C}$, the density of BCZT ceramics sintered at $1360^{\circ} \mathrm{C}$ was $5.34 \mathrm{~g} \mathrm{~cm}^{-3}$. The ceramic density continues to increase as the sintering temperature increases, where the maximum density is $5.68 \mathrm{~g} \mathrm{~cm}^{-3}$ at $1400^{\circ} \mathrm{C}$. The sintering density at $1400^{\circ} \mathrm{C}$ is $6.3 \%$ higher than that at $1360^{\circ} \mathrm{C}$. As the sintering temperature increases, the liquid phase between ceramics increases. A large number of pores are filled and the gas is discharged. The grain growth of ceramics at a sintering temperature of $1400^{\circ} \mathrm{C}$ is completed entirely, in which the stacking of the particles is compact, resulting in the maximum density. When the sintering temperature exceeds $1400^{\circ} \mathrm{C}$, as the temperature rises, it can be seen that the density of the ceramic decreases. The reason may be that the ceramic grains grow abnormally, while the matching degree between the particles 


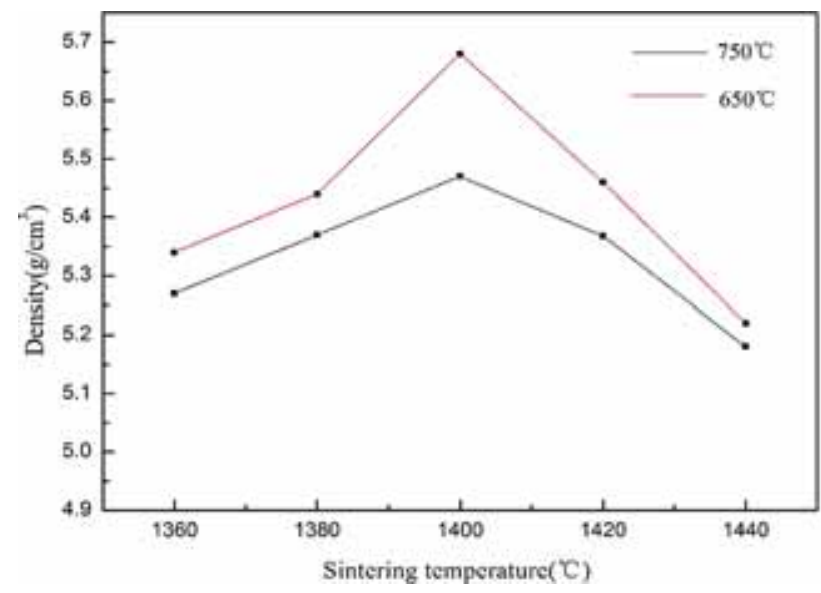

Figure 4. The density of BCZT ceramics at different sintering temperatures.

is lowered, resulting in an increase of ceramic defects. It can also be seen from the SEM image that too large particles tend to contain more bubbles, resulting in low density of the ceramic.

Figure 5 shows the SEM image of a BCZT ceramic sample obtained by calcining a powder at $650^{\circ} \mathrm{C}$ at different sintering temperatures. When the sintering temperature is $1360^{\circ} \mathrm{C}$, the average size of the particle of the ceramic is about $2 \mu \mathrm{m}$, while the largest particle size is $4-5 \mu \mathrm{m}$. However, it can be seen that there are lots of gaps and holes between the ceramic particles. When the sintering temperature rises to $1380^{\circ} \mathrm{C}$, the grain growth of the ceramic is relatively complete. The gap between the particles is shorter, so the density of the ceramic is increased. As the temperature continues to rise, the pores between the particles basically disappear. When the sintering temperature is $1420^{\circ} \mathrm{C}$, the ceramic particles have grown significantly. At $1440^{\circ} \mathrm{C}$, there are large holes on the ceramic surface, which indicates that some particles in the ceramic grow abnormally, resulting in defects on the ceramic surface.

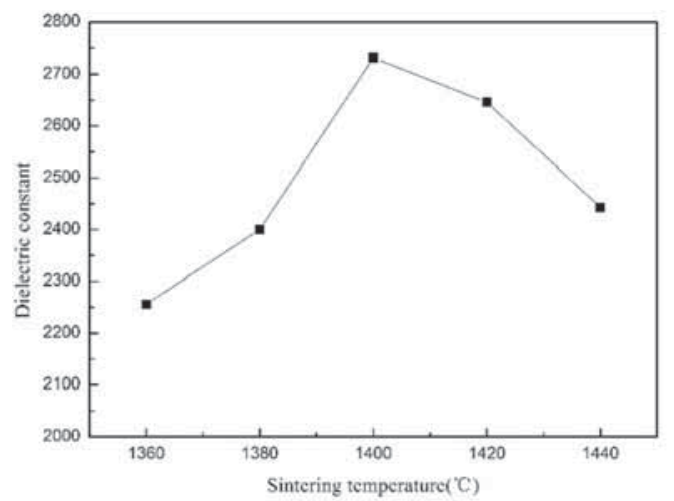

(a) $1 \mathrm{KHz}$

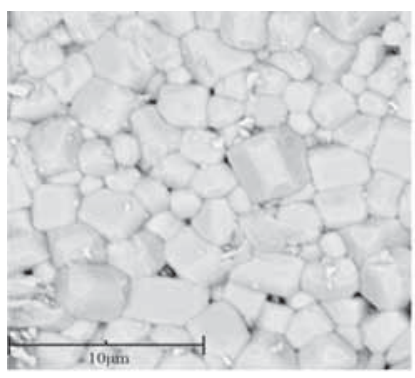

(a) $1360^{\circ} \mathrm{C}$

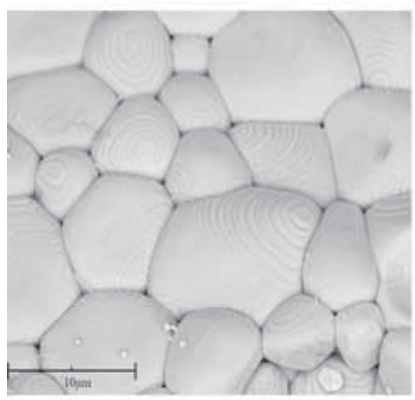

(c) $1400^{\circ} \mathrm{C}$

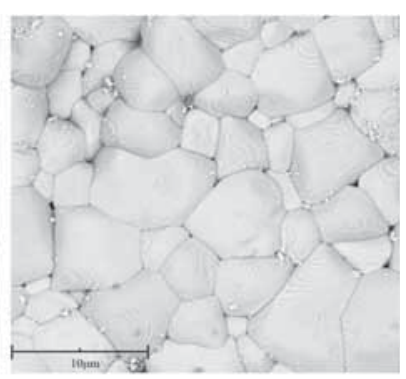

(b) $1380^{\circ} \mathrm{C}$

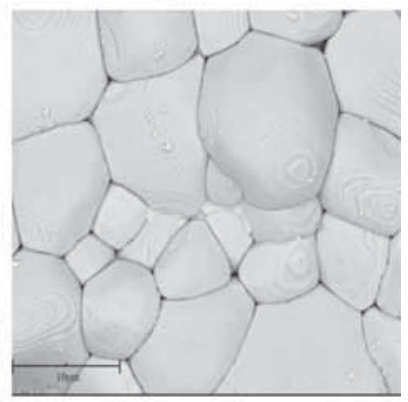

(d) $1420^{\circ} \mathrm{C}$

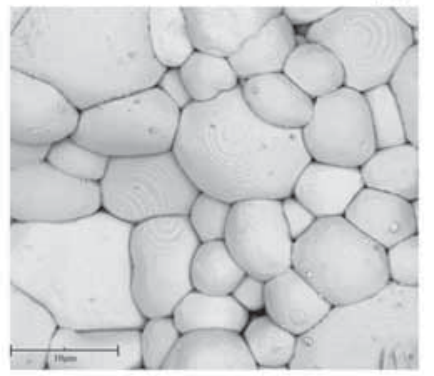

(e) $1440^{\circ} \mathrm{C}$

Figure 5. The SEM images of BCZT ceramics at different sintering temperatures.

Figure 6 shows the dielectric constant of BCZT ceramics with different sintering temperatures at $1 \mathrm{KHz}$ and $1 \mathrm{MHz}$. Under the $1 \mathrm{KHz}$ low-frequency alternating electric field, as

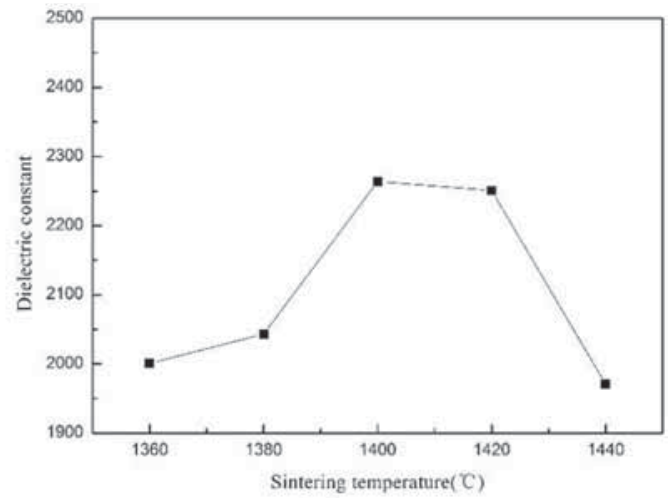

(b) $1 \mathrm{MHz}$

Figure 6. The dielectric constant of BCZT ceramics at different sintering temperatures. 


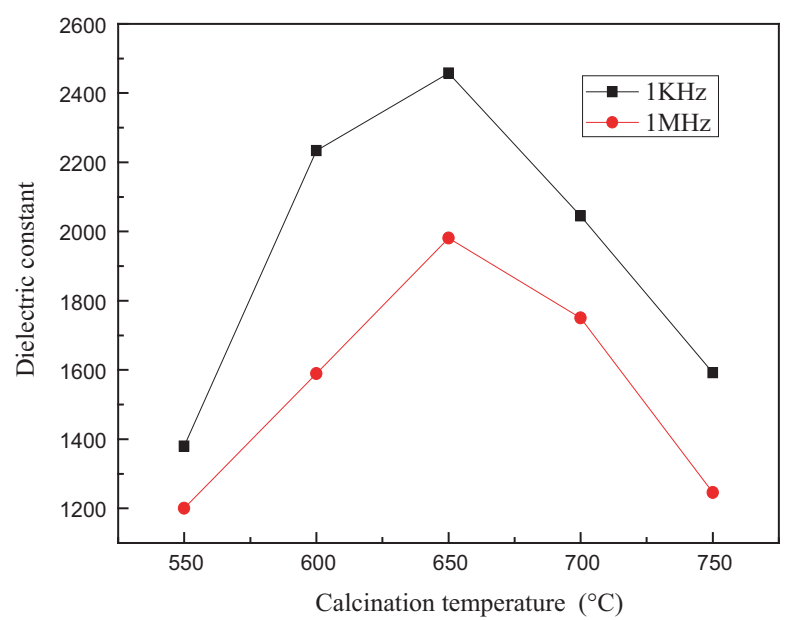

Figure 7. The dielectric constant of BCZT ceramics at different calcination temperatures.

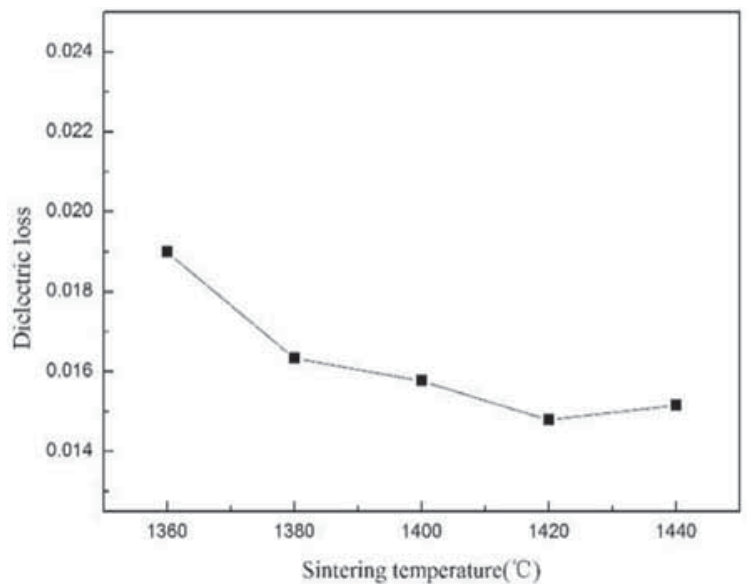

(a) $1 \mathrm{KHz}$

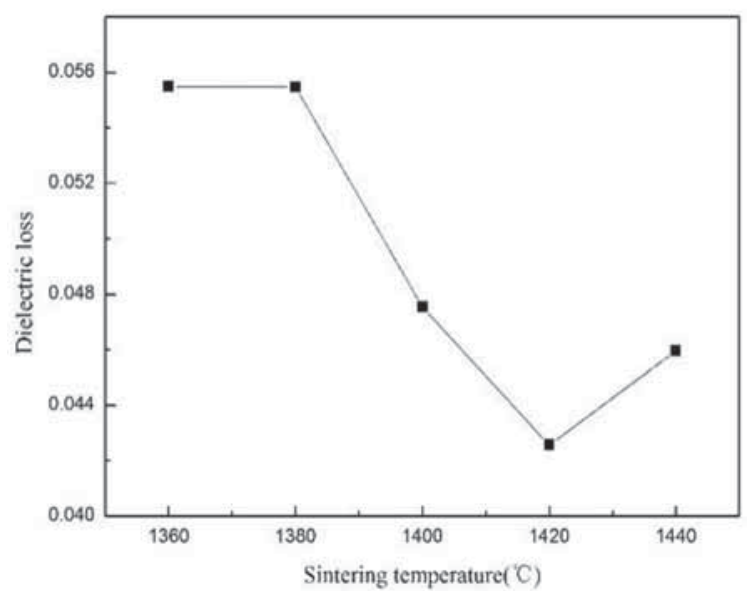

(b) $1 \mathrm{MHz}$

Figure 8. The dielectric loss of BCZT ceramics at different sintering temperatures.

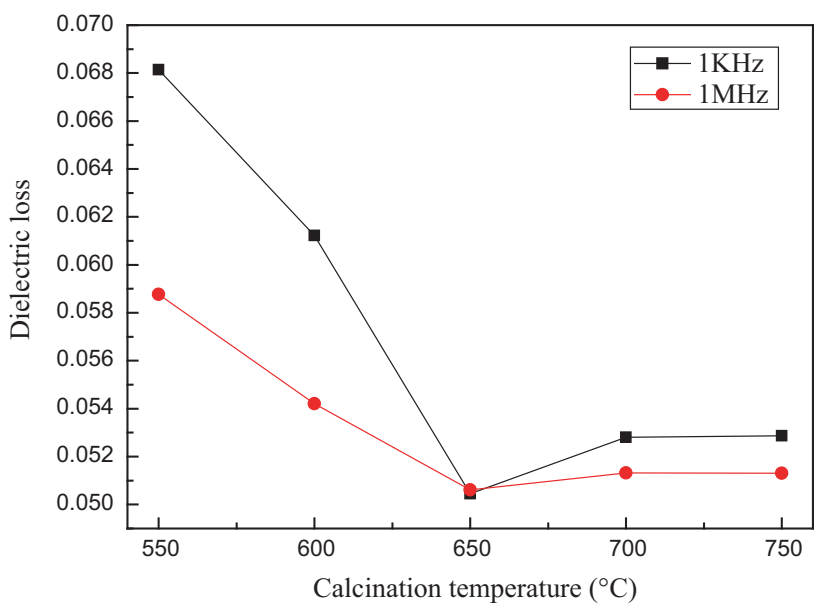

Figure 9. The dielectric loss of BCZT ceramics at different calcination temperatures.

shown in figure $6 \mathrm{a}$, the dielectric constant of BCZT ceramics increases first and then decreases with the increase of sintering temperature. The maximum dielectric constant of BCZT ceramics is 2458 at $1400^{\circ} \mathrm{C}$. Under the $1 \mathrm{MHz}$ high-frequency alternating electric field, the dielectric constant of BCZT ceramics reaches a maximum value of 1981 at $1400^{\circ} \mathrm{C}$.

Figure 7 shows the dielectric constant of BCZT ceramics at $1 \mathrm{KHz}$ and $1 \mathrm{MHz}$ alternating electric fields for different calcination temperatures. Under $1 \mathrm{KHz}$, when the calcination temperature was $550^{\circ} \mathrm{C}$, dielectric constant is 2012 . The dielectric constant of BCZT ceramics is 2732 at a calcination temperature of $650^{\circ} \mathrm{C}$. Here, the dielectric constant of BCZT ceramics increased by $35 \%$ with increasing calcination temperature. Then the dielectric constant of BCZT ceramics began to decrease. At a calcination temperature of $750^{\circ} \mathrm{C}$, the dielectric constant of BCZT ceramics was 1645, and the relative dielectric constant decreased by $39 \%$ compared to the maximum value. Under the high frequency alternating electric field of $1 \mathrm{MKz}$, the change trend of the dielectric constant of BCZT ceramics is basically consistent with low frequency electric fields. When the calcination temperature was $550^{\circ} \mathrm{C}$, the dielectric constant is 1380 . The dielectric constant of BCZT ceramics is 2458 at a calcination temperature of $650^{\circ} \mathrm{C}$. The dielectric constant of BCZT ceramics increased by $78 \%$ with an increase in calcination temperature. Then the dielectric constant of BCZT ceramics began to decrease. At a calcination temperature of $750^{\circ} \mathrm{C}$, the dielectric constant of BCZT ceramics is 1592 . The space charge and defects of the ceramics have an effect on the dielectric constant. The space charge and defects of the ceramics will be rearranged under the high electric field and will be trapped in a high-potential energy trap after polarization. Meanwhile, the contribution of the charge and defects to the dielectric constant of ceramics will disappear, resulting in a decrease of the dielectric constant of the ceramics. The dielectric constant is relatively high at a calcination temperature of $650^{\circ} \mathrm{C}$, which is due to high ceramic density at this temperature. The dielectric constant 
is not only related to the density of ceramics, but also have a great influence on the grain size, grain structure and internal defects. To obtain the perfect dielectric constant, ceramic grains, particle stacking and density must be coordinated.

Figure 8 shows the dielectric loss of BCZT ceramics with different sintering temperatures at $1 \mathrm{KHz}$ and $1 \mathrm{MHz}$, respectively. Under the $1 \mathrm{KHz}$ low-frequency alternating electric field, as shown in figure 8a, at a sintering temperature of $1360^{\circ} \mathrm{C}$, the dielectric loss is 0.01899 . As the sintering temperature increases, the dielectric loss of BCZT ceramics begins to decrease. When the sintering temperature was $1420^{\circ} \mathrm{C}$, the dielectric loss of BCZT ceramics reaches a minimum of 0.01479 . When the sintering temperature reaches $1440^{\circ} \mathrm{C}$, the dielectric loss of BCZT ceramics is 0.01516 .

Figure 9 exhibits the dielectric loss of BCZT ceramics at $1 \mathrm{KHz}$ and $1 \mathrm{MHz}$ alternating electric fields. At a calcination temperature of $550^{\circ} \mathrm{C}$, the dielectric loss of BCZT ceramics is the maximum for all calcination temperatures under the $1 \mathrm{KHz}$ alternating electric field, in which the dielectric of BCZT is 0.06814 . As the calcination temperature increases, the dielectric loss of BCZT ceramics began to decrease. Then the dielectric loss of BCZT ceramics shows an inflection point at a calcination temperature of $650^{\circ} \mathrm{C}$, where the dielectric loss shows the minimum value of 0.05045 . The value of the dielectric loss is reduced by $35 \%$ compared to the maximum value. However, the dielectric loss of BCZT ceramics increases again with an increase in calcination temperature. The dielectric loss of BCZT ceramics is 0.05287 at a calcination temperature of $750^{\circ} \mathrm{C}$, compared with a calcination temperature of $650^{\circ} \mathrm{C}$, while dielectric loss increased by $4.6 \%$. Under the high frequency alternating electric field of $1 \mathrm{MKz}$, the change trend of the dielectric constant of polarized BCZT ceramics is basically consistent with low frequency electric fields.

\section{Conclusions}

We describe a simple method to synthesize BCZT ceramics. The surface morphology, crystal phase composition and crystalline sizes are presented. The perovskite crystal structure mainly consists of rhombohedral phase and tetragonal phase. Calcination temperatures and sintering temperatures have a great influence on the morphology, architectures, crystallinity and grain size of the BCZT. The optimum calcination temperature is $650^{\circ} \mathrm{C}$. The dielectric constant of BCZT ceramics is
2732 at a calcination temperature of $650^{\circ} \mathrm{C}$, while the dielectric loss of BCZT ceramics shows the minimum value of 0.05045 . The results of this work suggest that the synthesized BCZT ceramics are helpful in the development of engineering application.

\section{Acknowledgements}

The authors would like to express their gratitude to the China postdoctoral programme (2017M611354), Heilongjiang Postdoctoral Fund (No. LBH-Z16045), Youth programme of Harbin University of Commerce (18XN027) and Young reserve talents of Harbin (RC2017QN017002).

\section{References}

[1] Takenaka T, Sakata K and Toda K 1990 Ferroelectrics 106375

[2] Li W, Xu Z J, Chu R Q, Fu P and Zang G Z 2012 Ceram. Int. 384353

[3] Li W, Xu Z J, Chu R Q, Fu P and Zang G Z 2011 J. Am. Ceram. Soc. 943181

[4] Yu Z, Ang C, Guo R Y and Bhalla A S 2002 J. Appl. Phys. 92 1489

[5] Liu Y W, Pu Y P and Sun Z X 2014 Mater. Lett. 137128

[6] Prabahar K, Ranjith R, Srinivas A, Kamat S V, Mallesham B, Niranjani V L et al 2017 Ceram. Int. 435356

[7] Yap E W, Glaum J, Oddershede J and Daniels J E 2018 Scripta Mater. 145122

[8] Li S B, Wang C B, Li L, Shen Q and Zhang L M 2017 J. Alloys Compd. 730182

[9] Liu X, Chen Z, Fang B, Ding J, Zhao X, Xu H et al 2015 J. Alloys Compd. $\mathbf{6 4 0} 128$

[10] Parjansri P, Intatha U and Eitssayeam S 2015 Mat. Res. Bull. 65 61

[11] Kantha P, Bunthod T, Jansrabua S, Barnthip N, Tigunta S, Pengpat K et al 2017 Appl. Mech. Mater. 866263

[12] Gao J, Li Q, Liu H, Shim J, Yan Q, Zhang Y et al 2015 Ceram. Int. 412497

[13] Zhang D, Gan Y, Chen T, Yang S and Zhang Y 2015 Ferroelectrics 48988

[14] Bai W, Hao J, Shen B and Zhai J 2013 Ceram. Int. 39 S19

[15] Kiatkittipong K, Scott J and Amal R 2011 Appl. Mater. Interfaces 33988

[16] Yu J G and Wang B 2010 Appl. Catal. B: Environ 94295

[17] Liao Y L, Que W X, Tang Z H, Wang W J and Zhao W H 2011 J. Alloys Compd. 5091054 